\title{
Obstructive sleep apnea and type 2 diabetes: is there a link?
}

\section{Sushmita Pamidi ${ }^{*}$ and Esra Tasali ${ }^{2}$}

${ }^{1}$ Respiratory Division, Department of Medicine, McGill University, Montreal, QC, Canada

${ }^{2}$ Department of Medicine, The University of Chicago, Chicago, IL, USA

\section{Edited by:}

Sigrid Veasey, University of Pennsylvania, USA

\section{Reviewed by:}

Vsevolod Polotsky, Johns Hopkins University, USA

Sigrid Veasey, University of

Pennsylvania, USA

\section{${ }^{*}$ Correspondence:}

Sushmita Pamidi, Respiratory

Division, McGill University Health

Centre, Room L4.05, 687 Pine

Avenue West, Montreal, OC, Canada H3A1A1.

e-mail: svpamidi@gmail.com
Type 2 diabetes is a chronic illness that is increasing in epidemic proportions worldwide. Major factors contributing to the development of type 2 diabetes include obesity and poor lifestyle habits (e.g., excess dietary intake and limited physical activity). Despite the proven efficacy of lifestyle interventions and the use of multiple pharmacological agents, the economic and public health burden of type 2 diabetes remains substantial. Obstructive sleep apnea (OSA) is a treatable sleep disorder that is pervasive among overweight and obese adults, who represent about two thirds of the U.S. population today. An evergrowing number of studies have shown that OSA is associated with insulin resistance, glucose intolerance and type 2 diabetes, independent of obesity. Evidence from animal and human models that mimic OSA provides potential mechanisms for how OSA may alter glucose metabolism. Up to $83 \%$ of patients with type 2 diabetes suffer from unrecognized OSA and increasing severity of OSA is associated with worsening glucose control. However, it is still unclear whether OSA may lead to the development of diabetes over time. More data from large-scale longitudinal studies with rigorous assessments of diabetes and OSA are needed. In addition, there is still controversy whether continuous positive airway pressure (CPAP) treatment of OSA improves glucose metabolism. Large-scale randomizedcontrolled trials of CPAP treatment of OSA with well-validated assessments of insulin sensitivity and glucose tolerance are needed. These studies may reveal that OSA represents a novel, modifiable risk factor for the development of prediabetes and type 2 diabetes.

Keywords: sleep apnea, diabetes, glucose, insulin, CPAP, cardiovascular
Obstructive sleep apnea (OSA) is a treatable sleep disorder that is pervasive among overweight and obese adults, who represent about two-thirds of the U.S. population today. Prevalence estimates of OSA in obese adults (aged 30-69 years) range from 11 to $46 \%$ in women and 33 to $77 \%$ in men (Young et al., 2005). Moreover, weight gain longitudinally predicts increased OSA incidence and severity (Peppard et al., 2000; Newman et al., 2005).

Over the past decade, there has been a rising interest in the cardiometabolic derangements associated with OSA (reviewed in Punjabi and Polotsky, 2005; Somers et al., 2008; Tasali and Ip, 2008; Tasali et al., 2008b; Jun and Polotsky, 2009; Levy et al., 2009). Current data suggests that OSA may play a role in adverse cardiovascular outcomes (Yaggi et al., 2005; Young et al., 2008; Redline et al., 2010). A large number of studies have shown that OSA is associated with insulin resistance, glucose intolerance, and type 2 diabetes, independent of obesity. In this article, we will review the current evidence from studies that address frequently asked questions regarding the links between OSA, type 2 diabetes, and prediabetic states.

\section{WHAT IS THE NATURAL HISTORY OF TYPE 2 DIABETES?}

Type 2 diabetes is a chronic illness that is increasing in epidemic proportions worldwide. It affects 25.6 million adults in the U.S., with an estimated 1.9 million new diagnoses per year [Center for Disease Control (CDC), 2011]. Major factors contributing to the development of type 2 diabetes include obesity and poor lifestyle habits (e.g., excess dietary intake and limited physical activity). The current standard criteria for the diagnosis of type 2 diabetes are as follows: (1) Hemoglobin A1c (A1c) $\geq 6.5 \%$, or (2) fasting plasma glucose $\geq 126 \mathrm{mg} / \mathrm{dl}$, or (3) $2 \mathrm{~h}$ plasma glucose $\geq 200 \mathrm{mg} / \mathrm{dl}$ during an oral glucose tolerance test (OGTT), or (4) random plasma glucose $\geq 200 \mathrm{mg} / \mathrm{dl}$ in a patient with classic symptoms of hyperglycemia [American Diabetes Association (ADA), 2010].

High glucose levels not sufficient to meet the diagnostic criteria for type 2 diabetes are considered as prediabetic states, namely impaired fasting glucose (IFG) and impaired glucose tolerance [IGT; American Diabetes Association (ADA), 2010]. According to the CDC, $35 \%$ of U.S. adults aged 20 years or older may have prediabetes, which suggests that prediabetic states exist in an estimated 79 million Americans [Center for Disease Control (CDC), 2011]. Fasting plasma glucose levels that are in the range of 100$125 \mathrm{mg} / \mathrm{dl}$ define an IFG state. A 2-h plasma glucose level during the 75-g OGTT that is in the range of $140-199 \mathrm{mg} / \mathrm{dl}$ defines an IGT state. In prediabetic states, the Alc ranges between 5.7 and 6.4\% [American Diabetes Association (ADA), 2010]. The hallmark of prediabetic states is insulin resistance. Transition from the early states of impaired glucose metabolism to frank diabetes may take 
Table 1 | Various methods used in the assessment of glucose metabolism*.

\begin{tabular}{ll}
\hline Method & Description \\
\hline Fasting plasma glucose & Plasma glucose and serum insulin levels are measured in \\
(FPG) and insulin & a fasting blood sample
\end{tabular}

Hemoglobin A1c (A1C)

Measured in a single blood sample and reflects glucose control over the preceding 2-3 months

Homeostatic model assessment (HOMA) index

Oral glucose tolerance test (OGTT)

Continuous glucose monitoring system

Hyperinsulinemic euglycemic clamp

Intravenous glucose tolerance test
The normalized product of fasting glucose and insulin calculated using the following formula: (fasting serum insulin $\times$ fasting plasma glucose)/22.5

After ingestion of $75 \mathrm{~g}$ of glucose, blood samples are collected for the measurement of glucose and insulin concentrations at time $30,60,90$, and $120 \mathrm{~min}$ to evaluate glucose tolerance

Glucose concentration in the interstitial fluid is measured using a subcutaneous sensor attached to a continuous monitoring device that record sensor signals every $5 \mathrm{~min}$, providing 288 glucose level readings per day

Insulin sensitivity is quantified by intravenous glucose infusion rate (i.e., glucose uptake by all the tissues in the body) under steady state conditions of euglycemia Glucose and insulin concentrations are measured during fasting and after intravenous glucose injection at frequent intervals for $4 \mathrm{~h}$

\section{Reliability and interpretation}

Impaired fasting glucose (IFG) is diagnosed if FPG is between 100 and $125 \mathrm{mg} / \mathrm{dl}$

Diabetes is diagnosed if fasting glucose levels are $\geq 126 \mathrm{mg} / \mathrm{dl}$ [American Diabetes Association (ADA), 2010]

Diabetes if hemoglobin $\mathrm{A} 1 \mathrm{C} \geq 6.5 \%$ Prediabetes if hemoglobin A1c is between 5.7 and 6.4\% [American Diabetes Association (ADA), 2010]

Monitoring of hemoglobin A1c is used in clinical practice for diabetes management and is the primary target for glycemic control

Lowering hemoglobin A1c below 7\% has been associated with a reduction of diabetic complications [American Diabetes

Association (ADA), 2010]

Reliable and validated estimate of insulin resistance (Matthews et al., 1985)

Elevated HOMA levels reflect higher degrees of insulin resistance

A clinical tool used for the diagnosis of type 2 diabetes

[American Diabetes Association (ADA), 2010]

Normal glucose tolerance (NGT), impaired glucose tolerance

(IGT), or diabetes is diagnosed if the glucose level at $2 \mathrm{~h}$ is less than $140 \mathrm{mg} / \mathrm{dl}$, between $140-199 \mathrm{mg} / \mathrm{dl}$, or $200 \mathrm{mg} / \mathrm{dl}$ or more, respectively

Used in clinical practice for diabetes management to assess

$24 \mathrm{~h}$ glucose fluctuations (particularly post-prandial and

nocturnal levels)

The gold standard technique used for measurement of insulin sensitivity (DeFronzo et al., 1979)

Validated tool that allows to simultaneously assess glucose tolerance, beta-cell responsiveness, and insulin sensitivity using a mathematical model (Bergman, 2005)

${ }^{*}$ Reprinted with permission of the American Thoracic Society. Copyright @ 2008 American Thoracic Society.

Tasali and Ip (2008), An official Journal of The American Thoracic Society.

several years, and it is estimated that $\sim 70 \%$ prediabetic individuals eventually develop type 2 diabetes (Nathan et al., 2007). The most commonly used clinical and research methods to assess glucose tolerance, insulin sensitivity, and secretion are summarized in Table 1.

In normal individuals, insulin resistance is compensated by an up-regulation of insulin secretion to maintain normal glucose tolerance. According to the "hyperbolic law of glucose tolerance," under normal conditions the product of insulin sensitivity and secretion (i.e., the disposition index; DI) is constant (Bergman, 2005). In individuals who are at risk for developing type 2 diabetes, the DI may be reduced due to inadequate compensatory insulin secretion for a given degree of insulin resistance. Thus, type 2 diabetes is a two-step process characterized by both insulin resistance and impaired insulin secretion. Initially, insulin resistance occurs resulting in progression from a normal glucose tolerant state to IGT. At this stage, insulin levels are elevated (compensatory hyperinsulinemia) and beta-cell dysfunction is already present. Subsequently, progressive decline in beta-cell function occurs, which leads to development of type 2 diabetes (DeFronzo and Abdul-Ghani, 2011).

Despite the proven efficacy of lifestyle interventions and the use of multiple pharmacological agents, the economic and public health burden of type 2 diabetes remains substantial. Cardiovascular disease is a major cause of mortality and morbidity in both type 2 diabetes and prediabetes. In addition to cardiovascular disease, type 2 diabetes is associated with longterm complications affecting the eyes, kidneys, and nervous system. (Kashyap and Defronzo, 2007; Nathan et al., 2007; Mazzone et al., 2008). It is well documented that both lifestyle modification and metformin use are effective in reducing the incidence of diabetes (Tuomilehto et al., 2001; Knowler et al., 2002, 2009). However, even with substantial efforts to achieve lifestyle modification, data suggest that the effectiveness of this intervention diminishes over time. Thus, the 
development of additional strategies to prevent or delay the onset of diabetes and its cardiovascular complications remains a critical public heath challenge.

\section{WHAT IS THE PREVALENCE OF OSA IN TYPE 2 DIABETICS?}

The overall prevalence of OSA diagnosed by full polysomnography in type 2 diabetic patients is approximately $71 \%$ based on the average of data from five studies including a total number of nearly 1200 type 2 diabetic patients (Resnick et al., 2003; Einhorn et al., 2007; Foster et al., 2009; Laaban et al., 2009; Aronsohn et al., 2010; Table 2). The highest estimate of $86 \%$ was reported in obese diabetic patients enrolled in the multi-center Sleep AHEAD study (Foster et al., 2009). The lowest estimate of 58\% was found in the Sleep Heart Health Study (Resnick et al., 2003), which is a multi-center cohort that included older individuals (with more than half aged over 65 years) and used self-reported diabetes and a desaturation criteria of $4 \%$ for the definition of hypopneas. In another study by Aronsohn et al., OSA prevalence was found to be $77 \%$ using a less stringent cut-off of $3 \%$ for oxygen desaturations. Of note, when the dataset was re-analyzed using more strict $4 \%$ desaturation criteria, this estimate was reduced to 58\% (Aronsohn et al., 2010). These variable prevalence estimates may be due to differences in study populations as well as different scoring criteria used to capture OSA (Redline et al., 2000). Nevertheless, considering that the prevalence of OSA by full-night polysomnography in patients with type 2 diabetes averages $71 \%$, this would then suggest that approximately 19 million diabetics may have undiagnosed and untreated OSA. Indeed, a recent retrospective analysis of a total of 16,066 diabetic patients with one or more primary care office visits in 27 primary care ambulatory practices has revealed that only $18 \%$ of the study population (23\% of obese patients) carried an OSA diagnosis (Heffner et al., 2012). These findings suggest that in the primary care setting, OSA is largely unrecognized in patients with diabetes and thus millions of diabetics may currently suffer from this co-morbidity. In sum, these staggering statistics emphasize the need for a better understanding of the links between OSA and type 2 diabetes (Shaw et al., 2008).

\section{WHAT IS THE PREVALENCE AND INCIDENCE OF TYPE 2 DIABETES IN OSA?}

Several population and clinic-based studies have assessed the prevalence and incidence of type 2 diabetes in OSA (Meslier et al., 2003; Reichmuth et al., 2005; Seicean et al., 2008; Tamura et al., 2008; Botros et al., 2009; Mahmood et al., 2009; Marshall et al., 2009; Ronksley et al., 2009; Celen et al., 2010; Fredheim et al., 2011). The majority of these studies have used validated diabetes definitions based on fasting glucose or $2 \mathrm{~h}$ post-challenge glucose levels, while a few studies relied on self-reported diabetes and/or antidiabetic medication use. Most, but not all studies (Marshall et al., 2009; Ronksley et al., 2009; Celen et al., 2010), used full polysomnography to diagnose OSA. The majority of studies used statistical adjustments for shared risk factors such as age, sex, body mass index (BMI) and various other parameters (e.g., neck and waist circumference). Overall, the cross-sectional analyses have shown a significantly higher prevalence of diabetes in patients with OSA as compared to those without OSA. The prevalence estimates range from 15 to $30 \%$, depending on the study population, the definition of OSA severity, and the methods used to diagnose type 2 diabetes (Meslier et al., 2003; Reichmuth et al., 2005; Mahmood et al., 2009; Ronksley et al., 2009; Fredheim et al., 2011). A few studies have also reported a significant relationship between increasing severity of OSA and the prevalence of diabetes (Reichmuth et al., 2005; Tamura et al., 2008; Ronksley et al., 2009; Samson et al., 2012). In two studies (Mahmood et al., 2009; Marshall et al., 2009), the higher odds ratio for diabetes in patients with OSA was no longer significant after controlling for confounders. In one study (Ronksley et al., 2009), a higher adjusted odds of selfreported diabetes was found only in the severe OSA group who had excessive sleepiness. In this regard, more research is needed to elucidate the role of sleepiness in adverse metabolic outcomes and

Table 2 | Studies examining the prevalence of obstructive sleep apnea (OSA) in patients with type 2 diabetes.

\begin{tabular}{|c|c|c|c|c|}
\hline Author/year & Sample characteristics & $\begin{array}{l}\text { OSA diagnosis } \\
\text { criteria }\end{array}$ & Diabetes definition & Prevalence estimates \\
\hline Resnick et al. (2003) & $\begin{array}{l}n=470 \text { (216 men) } \\
\text { Sleep Heart Health Study, USA }\end{array}$ & $\mathrm{AHI} \geq 5$ & $\begin{array}{l}\text { Self-reported; Use of } \\
\text { diabetes medications }\end{array}$ & $\begin{array}{l}58 \% \text { with at least mild OSA }(A H I \geq 5) \\
24 \% \text { with moderate-severe } O S A(A H I \geq 15)\end{array}$ \\
\hline Einhorn et al. (2007) & $\begin{array}{l}n=62 \text { (31 men) } \\
\text { Diabetes clinics }\end{array}$ & $\mathrm{AHI} \geq 5$ & Not reported & $\begin{array}{l}71 \% \text { with at least mild OSA }(\mathrm{AHI} \geq 5) \\
61 \% \text { with moderate-severe OSA }(\mathrm{AHI} \geq 15)\end{array}$ \\
\hline Foster et al. (2009) & $\begin{array}{l}n=305 \text { (122 men) } \\
\text { Obese patients with type } 2 \\
\text { diabetes enrolled in Sleep } \\
\text { AHEAD trial }\end{array}$ & $\mathrm{AHI} \geq 5$ & $\begin{array}{l}\text { Self-reported with } \\
\text { verification }\end{array}$ & $\begin{array}{l}\text { 86.6\% Overall prevalence } \\
33.4 \% \text { Mild OSA } \\
\text { 30.5\% Moderate OSA } \\
22.6 \% \text { Severe OSA }\end{array}$ \\
\hline Laaban et al. (2009) & $\begin{array}{l}n=303 \text { (155 men) } \\
\text { Poorly controlled type } 2 \\
\text { diabetics from clinics }\end{array}$ & $\mathrm{AHI} \geq 5$ & $\begin{array}{l}\text { Documented medical } \\
\text { history of diabetes }\end{array}$ & $\begin{array}{l}\text { 63\% Overall prevalence } \\
\text { 34\% Mild OSA } \\
\text { 19\% Moderate OSA } \\
10 \% \text { Severe OSA }\end{array}$ \\
\hline Aronsohn et al. (2010) & $\begin{array}{l}n=60 \text { ( } 27 \text { men) } \\
\text { Primary care and endocrinology } \\
\text { clinics }\end{array}$ & $\mathrm{AHI} \geq 5$ & Physician diagnosis & $\begin{array}{l}\text { 77\% Overall prevalence } \\
38 \% \text { Mild OSA } \\
25 \% \text { Moderate OSA } \\
13 \% \text { Severe OSA }\end{array}$ \\
\hline
\end{tabular}


Table 3 | Prospective studies examining the incidence of type 2 diabetes in patients with obstructive sleep apnea (OSA).

\begin{tabular}{|c|c|c|c|c|c|}
\hline Author/year & $\begin{array}{l}\text { Sample } \\
\text { characteristics }\end{array}$ & $\begin{array}{l}\text { OSA diagnosis } \\
\text { criteria }\end{array}$ & $\begin{array}{l}\text { Diabetes } \\
\text { definition }\end{array}$ & $\begin{array}{l}\text { Follow-up } \\
\text { period }\end{array}$ & Main findings \\
\hline $\begin{array}{l}\text { Reichmuth } \\
\text { et al. (2005) }\end{array}$ & $\begin{array}{l}1387 \text { (779 men); } \\
\text { Wisconsin Sleep } \\
\text { Cohort, USA }\end{array}$ & $\mathrm{AHI} \geq 5$ & $\begin{array}{l}\text { Physician diagnosis; } \\
\text { Fasting glucose } \geq 126 \mathrm{mg} / \mathrm{dl}\end{array}$ & $\begin{array}{l}4 \text { years } \\
(n=987)\end{array}$ & $\begin{array}{l}\text { In unadjusted analysis, higher incidence of } \\
\text { diabetes in moderate to severe OSA. } \\
\text { Unadjusted OR }=4.06(\mathrm{Cl}=1.86-8.85) \\
\text { After adjustments for age, sex, body habitus, no } \\
\text { increase in diabetes incidence. } \\
\text { Adjusted OR }=1.62(\mathrm{Cl}=0.67-3.65)\end{array}$ \\
\hline $\begin{array}{l}\text { Marshall } \\
\text { et al. (2009) }\end{array}$ & $\begin{array}{l}399 \text { (294 men); } \\
\text { Busselton Health } \\
\text { Study, Australia }\end{array}$ & $\begin{array}{l}\text { AHI } \geq 5 \text { (limited } \\
\text { PSG) }\end{array}$ & $\begin{array}{l}\text { Physician diagnosis; Use of } \\
\text { diabetes medications; } \\
\text { Fasting glucose } \geq 126 \mathrm{mg} / \mathrm{dl}\end{array}$ & 4 years & $\begin{array}{l}\text { After adjustments for age, sex, BMI, waist, mean } \\
\text { blood pressure, HDL cholesterol, higher incidence } \\
\text { of diabetes in moderate to severe OSA. } \\
\text { Adjusted OR }=13.45(\mathrm{Cl}=1.59-114.11)\end{array}$ \\
\hline $\begin{array}{l}\text { Botros et al. } \\
\text { (2009) }\end{array}$ & $\begin{array}{l}544 \text { individuals; VA } \\
\text { Connecticut Sleep } \\
\text { Center, USA }\end{array}$ & $\begin{array}{l}\mathrm{AHI} \geq 8 \text { (full } \\
\mathrm{PSG})\end{array}$ & $\begin{array}{l}\text { Physician diagnosis; } \\
\text { Fasting glucose } \geq 126 \mathrm{mg} / \mathrm{dl}\end{array}$ & 2.7 years & $\begin{array}{l}\text { After adjustments for age, sex, race, BMI, baseline } \\
\text { fasting glucose, weight change, higher incidence of } \\
\text { diabetes with increasing severity of OSA. } \\
\text { Adjusted Hazard Ratio per quartile of OSA } \\
\text { severity }=1.43(\mathrm{Cl}=1.10-1.86)\end{array}$ \\
\hline $\begin{array}{l}\text { Celen et al. } \\
(2010)\end{array}$ & $\begin{array}{l}168 \text { middle-age } \\
\text { adults, sleep } \\
\text { clinics, Sweden }\end{array}$ & $\begin{array}{l}\mathrm{OD} \geq 30 \text { (limited } \\
\text { PSG) }\end{array}$ & Physician diagnosis & 16 years & $\begin{array}{l}\text { Significantly higher incidence of diabetes in } \\
\text { patients with OSA compared to no OSA only in } \\
\text { women but not in men }\end{array}$ \\
\hline $\begin{array}{l}\text { Lindberg } \\
\text { et al. (2012) }\end{array}$ & $\begin{array}{l}156 \text { men, } \\
\text { population-based } \\
\text { cohort, Sweden }\end{array}$ & $\mathrm{AHI}>5$ & $\begin{array}{l}\text { Self-reported; Regular } \\
\text { doctor visits for diabetes; } \\
\text { Fasting glucose } \geq 126 \mathrm{mg} / \mathrm{dl}\end{array}$ & 11 years & $\begin{array}{l}\text { At the follow-up, } 23 \text { men had diabetes } \\
\text { After adjustment for age, baseline BMI, change in } \\
\text { BMI, hypertension, and years with CPAP, } \\
\text { increasing severity of oxygen desaturations is a } \\
\text { predictor of developing diabetes. } \\
\text { Adjusted } \mathrm{OR}=4.4(\mathrm{Cl}=1.1-18.1)\end{array}$ \\
\hline
\end{tabular}

AHI, apnea-hypopnea index; CPAP, continuous positive airway pressure; $O D$, oxygen desaturations.

to better understand the links between OSA and diabetes in sleepy versus non-sleepy patients.

A total of five prospective studies have examined the incidence of type 2 diabetes in patients with OSA (Table 3). In the longitudinal follow-up of about 1000 individuals from the Wisconsin Sleep Cohort (Reichmuth et al., 2005), OSA was found to be a risk factor for incident diabetes over a 4 -year period, but this association was no longer significant after adjusting for age, sex, and body habitus. The Busselton Health Study (Marshall et al., 2009) reported a significant independent association between moderate to severe OSA and incident diabetes over a 4-year follow-up period, but the sample size was small with only a few incident cases of diabetes. In another study by Botros et al. (2009), an independent association between OSA and incident diabetes was found after adjusting for age, sex, race, BMI, baseline fasting glucose and weight change over a mean follow-up period of 2.7 years. Interestingly, one clinic-based study of 168 middle-aged patients (Celen et al., 2010), reported a significantly higher incidence of diabetes in patients with OSA compared to those without OSA in women, but not in men, after a follow-up period of 16 years. More recently, in a population-based cohort of 156 men from Sweden (Lindberg et al., 2012), the increasing severity of oxygen desaturations in OSA was found to be a predictor of developing diabetes after adjustments for various confounders including years of treatment for OSA. In another prospective study of about 4000 middle-aged individuals, nocturnal intermittent hypoxia was associated with an increased risk of developing type 2 diabetes after a 3-year median follow-up (Muraki et al., 2010).

Thus, the current evidence from cross-sectional analyses suggest that type 2 diabetes is more prevalent among patients with OSA compared to those without OSA, independent of shared risk factors. However, it is still unclear whether OSA may lead to the development of diabetes over time. More data from large-scale longitudinal studies with rigorous assessments of diabetes and OSA are needed.

\section{DOES UNTREATED OSA ADVERSELY AFFECT GLYCEMIC CONTROL IN TYPE 2 DIABETIC PATIENTS?}

An earlier study including 279 diabetic patients found no significant associations between OSA and glycemic control, as assessed by Alc (Einhorn et al., 2007). In this negative study, only about $22 \%$ of the study population was assessed by full polysomnography and the duration of sleep recording was reported to be as low as $4 \mathrm{~h}$. In a more recent study (Aronsohn et al., 2010), 60 patients with physician-diagnosed diabetes underwent full laboratory polysomnography (with a minimum laboratory recording time of $7 \mathrm{~h}$ ) to assess the presence and severity of OSA. Increasing severity of untreated OSA was associated with poorer glucose control after controlling for age, sex, race, BMI, number of diabetes medications, level of exercise, years of diabetes, and total sleep time. Compared to patients without OSA (adjusted mean A1c: $5.7 \%$ ), the adjusted mean A1c was $7.3 \%$ in mild OSA, $7.7 \%$ 
in moderate OSA, and $9.7 \%$ in severe OSA. Importantly, the magnitude of these associations is comparable, if not exceeding to those of widely used hypoglycemic medications. Of note, when only the first $4 \mathrm{~h}$ of recording was analyzed, the robust relationship between OSA severity and A1c was no longer apparent, perhaps due to insufficient recording time for REM sleep to occur. This would suggest that sleep recordings longer than the commonly used minimum of $4 \mathrm{~h}$ might be needed for better assessment of the links between OSA and type 2 diabetes. Another cross-sectional study (Pillai et al., 2011) involving 52 consecutive patients recruited from a diabetes-obesity clinic found that after adjusting for age, gender, BMI, duration of diabetes, and insulin dose, increased severity of OSA was associated with increased Alc levels. The adjusted mean values of A1c in each OSA category were $8.62 \%$ for no OSA, $9.36 \%$ for mild, $10.61 \%$ for moderate, and $9.91 \%$ for severe OSA. In a smaller study (Fendri et al., 2011) of 26 overweight and obese individuals with type 2 diabetes, nocturnal glycemia (as assessed by a continuous glucose monitoring sensor) was found to be $38 \%$ higher in those who had OSA, compared to those without OSA, independent of BMI.

Overall, there is evidence to suggest that the presence and severity of untreated OSA may be associated with poor glucose control in type 2 diabetic patients. These findings may have important clinical implications in the management and care of type 2 diabetes as they support the hypothesis that reducing the severity of OSA may be an adjunct therapeutic strategy to optimize glucose control.

\section{IS THE PRESENCE AND SEVERITY OF OSA ASSOCIATED WITH PREDIABETIC STATES SUCH AS INSULIN RESISTANCE AND GLUCOSE INTOLERANCE?}

Over the past few decades, an increasing number of studies from population and clinic-based cohorts have consistently found a robust independent association between the presence and severity of OSA and prediabetic states such as insulin resistance and glucose intolerance. A comprehensive review of all these studies is beyond the scope of this article, but has been the topic of several review articles (Punjabi and Polotsky, 2005; Tasali and Ip, 2008; Jun and Polotsky, 2009; Levy et al., 2009; Punjabi, 2009; Pamidi et al., 2010). In the majority of these studies the estimation of insulin sensitivity was based on the homeostatic model assessment (HOMA) index, which is a normalized product of fasting glucose and insulin levels. Several studies have also used the OGTT to assess glucose and insulin response after glucose ingestion. Interestingly, many of these studies were conducted in men, so the data on possible gender effects in the associations between OSA, insulin resistance, and glucose intolerance is lacking. In the majority of studies, commonly used indices of OSA severity were the apneahypopnea index (AHI) and the frequency as well as the degree of intermittent hypoxia.

Overall, the prevalence of prediabetes (i.e., the presence of either IFG and/or IGT) was found to be significantly higher in patients with OSA than those without OSA, but the estimates have been variable, ranging between 20 and 67\% (Meslier et al., 2003; Kono et al., 2007; Seicean et al., 2008; Tamura et al., 2008; Fredheim et al., 2011). In a large cross-sectional analysis of a subset of data from the Sleep Heart Health Study, involving over 2500 non-diabetic individuals (Seicean et al., 2008), the presence of OSA was associated with a significantly higher odds of IFG and IGT after controlling for age, sex, race, BMI, and waist circumference. Importantly, the magnitude of these associations was similar in non-overweight and overweight individuals (Seicean et al., 2008).

In the earliest studies from large population-based samples, OSA was found to be independently associated with insulin resistance (Ip et al., 2002; Punjabi et al., 2002) and glucose intolerance (Punjabi et al., 2002). In a clinic-based sample of 595 men, the increasing severity of OSA was associated with worsening glucose tolerance and insulin resistance, independent of age and BMI (Meslier et al., 2003). In an earlier report from the Sleep Heart Health Study, the increasing severity of OSA was independently associated with both fasting and $2 \mathrm{~h}$ post-load glucose levels during an OGTT (Punjabi et al., 2004). In a population-based sample of 400 women, those with severe OSA had significantly lower insulin sensitivity as compared to those without OSA, and the severity of OSA was associated with increasing fasting and 2-h post-challenge insulin levels during an OGTT, after adjusting for age, waist-hip ratio, and other potential confounders (TheorellHaglow et al., 2006). In an analysis of a subset of participants in the Wisconsin Sleep Cohort Study $(n=546)$, OSA was significantly associated with insulin resistance as measured by the HOMA index (Nieto et al., 2009). More recently, Punjabi and Beamer (2009) estimated insulin sensitivity in 118 non-diabetic adults using a frequently sampled intravenous glucose tolerance test (ivGTT). The authors found that compared to normal individuals, those with mild, moderate, and severe OSA showed a 26.7, 36.5 , and $43.7 \%$ decrease in insulin sensitivity, respectively, after controlling for age, gender, race, and percent body fat. Despite this progressive decline in insulin sensitivity, the acute insulin response to glucose was unchanged, suggesting an insufficient up-regulation of insulin secretion and thus impaired beta-cell function. A recent cross-sectional study of 1,599 non-diabetic patients, where participants with an A1c of $\geq 6.5 \%$, self-reported diabetes or use of diabetic medication were excluded, a doseresponse relationship between OSA severity and the percentage of patients with Alc $>6 \%$ was observed, suggesting a gradual increase in prediabetic state with increasing severity of OSA (Priou et al., 2012). Although some of these studies have controlled for adiposity using several surrogate markers (e.g., waist circumference, percent body fat), central adiposity, particularly visceral fat is an important confounding factor in the observed links between OSA and prediabetic states. In this regard, there is some evidence to suggest that in the absence of confounding effects of visceral adiposity, OSA may still be associated with insulin resistance and higher fasting glucose levels (Kono et al., 2007).

A recent study by Pamidi et al. (2012), the researchers assessed whether the presence of OSA affects glucose metabolism in young, lean individuals who are healthy and free of cardiometabolic disease. In a prospective design, 52 healthy men (age range 1830 years and BMI range $18-25 \mathrm{~kg} / \mathrm{m}^{2}$ ) underwent a laboratory polysomnogram followed by a morning OGTT to assess glucose metabolism. All subjects were stratified according to the 
presence or absence of ethnicity-based diabetes risk and family history of diabetes. The authors then used a frequency matching approach and randomly selected individuals without OSA, yielding a total of 20 control men without OSA and 12 men with OSA. Men with OSA and controls were similar in terms of age, BMI, ethnicity-based diabetes risk, family history of diabetes, and level of exercise. Both groups had normal systolic and diastolic blood pressure and fasting lipid levels. Following ingestion of a 75-g glucose load, men with OSA had 27\% lower insulin sensitivity (estimated by the Matsuda index during the OGTT) and 37\% higher total insulin secretion than the controls, despite comparable glucose levels. This study is the first to demonstrate that in young lean men (mean age $<24$ years, mean BMI $<23 \mathrm{~kg} / \mathrm{m}^{2}$ ) who are otherwise healthy and free of cardiometabolic disease, the presence of OSA is associated with insulin resistance and compensatory hyperinsulinemia to maintain normal glucose homeostasis. These findings provide evidence to support the hypothesis that OSA may be associated with early changes in the natural history of type 2 diabetes even in the absence of obesity, cardiovascular disease, and other known risk factors for type 2 diabetes.

In summary, these observational studies strongly support an association between OSA and insulin resistance and glucose intolerance, even after statistical adjustments for shared risk factors. However, central adiposity, particularly visceral fat, needs to be considered as an important confounder when interpreting these studies. Finally, studies with longitudinal and interventional designs are needed to better address the potential role of OSA in the development of prediabetic states.

\section{IS CPAP TREATMENT OF OSA EFFECTIVE IN IMPROVING GLUCOSE METABOLISM? EVIDENCE FROM UNCONTROLLED STUDIES}

In patients with type 2 diabetes, five uncontrolled studies including a total of 87 patients examined the effects of continuous positive airway pressure (CPAP) on glycemic control (Brooks et al., 1994; Harsch et al., 2004; Babu et al., 2005; Dawson et al., 2008; Pallayova et al., 2008). Two studies reported improvements in nighttime glucose levels after one night (Pallayova et al., 2008) and 5 weeks (Dawson et al., 2008) of CPAP use. Two other studies showed improvements in insulin sensitivity (as assessed by the gold standard hyperinsulinemic euglycemic clamp), without a change in A1c levels after 3-4 months of CPAP (Brooks et al., 1994; Harsch et al., 2004). In contrast, Babu et al. (2005) found an improvement in A1c and post-prandial glucose levels after 3 months of CPAP therapy in 25 obese patients with type 2 diabetes. Notably, in patients who used CPAP for more than $4 \mathrm{~h} /$ night (averaging $\sim 6.6 \mathrm{~h} /$ night) the decrease in Alc levels was strongly correlated with the amount of CPAP use (Babu et al., 2005). One observational cohort study examined the effect of CPAP on incident diabetes and found that among patients with moderate to severe OSA, the regular use of CPAP (determined by physician follow-up) was associated with a significant reduction of incident diabetes, even after adjusting for subsequent weight loss during an average of 2.7-year follow-up period (Botros et al., 2009).
In non-diabetic patients with OSA, numerous uncontrolled studies have examined the effects of CPAP treatment on prediabetic states such as glucose tolerance and insulin sensitivity. While some studies have reported positive findings (Harsch et al., 2004; Lindberg et al., 2006; Barcelo et al., 2008; Dorkova et al., 2008; Schahin et al., 2008; Cuhadaroglu et al., 2009; Henley et al., 2009; Oktay et al., 2009; Steiropoulos et al., 2009b; Mota et al., 2011; Tasali et al., 2011; Shpirer et al., 2012), others were negative (Saini et al., 1993; Cooper et al., 1995; Stoohs et al., 1996; Saarelainen et al., 1997; Ip et al., 2000; Smurra et al., 2001; Czupryniak et al., 2005; Trenell et al., 2007; Vgontzas et al., 2008; Carneiro et al., 2009; Comondore et al., 2009; Murri et al., 2009; Garcia et al., 2011). The majority of studies used the HOMA index (relying on fasting insulin and glucose levels) as a measure of insulin sensitivity (Czupryniak et al., 2005; Lindberg et al., 2006; Trenell et al., 2007; Barcelo et al., 2008; Dorkova et al., 2008; Carneiro et al., 2009; Comondore et al., 2009; Cuhadaroglu et al., 2009; Henley et al., 2009; Murri et al., 2009; Steiropoulos et al., 2009b; Tasali et al., 2011), while only a few studies used the gold standard hyperinsulinemic euglycemic clamp method (Saarelainen et al., 1997; Smurra et al., 2001; Harsch et al., 2004; Schahin et al., 2008) and one study used the ivGTT (Tasali et al., 2011). Three studies have used the standard OGTT method to assess post-challenge glucose tolerance (Smurra et al., 2001; Henley et al., 2009; Shpirer et al., 2012). The average CPAP treatment period ranged between one night and 6 months, with one study reporting findings after almost 3 years of follow-up (Schahin et al., 2008). Notably, only about half of the studies reported objective data on CPAP use and the overall reported average CPAP adherence was about $4-5 \mathrm{~h} /$ night. Most studies were conducted in obese men. In one study, CPAP improved insulin sensitivity (assessed by hyperinsulinemic euglycemic clamp) in 40 men even after 2 days of therapy (Harsch et al., 2004) and the improvement persisted at 3-months, particularly in those with a BMI less than $30 \mathrm{~kg} / \mathrm{m}^{2}$. In contrast, an earlier study (Smurra et al., 2001) using the hyperinsulinemic euglycemic clamp and OGTT in 16 obese men found no change in insulin sensitivity or glucose tolerance after 2 months of CPAP. A few studies reported a positive effect of CPAP on insulin sensitivity in subgroups of patients, specifically those who used CPAP for more than $4 \mathrm{~h} /$ night (Dorkova et al., 2008; Steiropoulos et al., 2009a) or those with excessive daytime sleepiness (Barcelo et al., 2008). In one study, 8 weeks of CPAP treatment (average CPAP use $\sim 6.6 \mathrm{~h} /$ night) modestly improved insulin sensitivity (as assessed by ivGTT) in young women with polycystic ovarian syndrome despite morbid obesity (Tasali et al., 2011). Importantly, the change in insulin sensitivity correlated positively with CPAP use and negatively with BMI. In addition, both daytime and nighttime norepinephrine levels were decreased after CPAP and the reductions were greater with increased CPAP use, suggesting that the metabolic effects of CPAP therapy may be modulated by the hours of CPAP use and the degree of obesity (Tasali et al., 2011).

Overall, the uncontrolled studies that examined the effect of CPAP therapy on glucose metabolism have yielded mixed results. This could be partly explained by differences in patient population and techniques used to assess glucose metabolism as well as small sample size, poor adherence to CPAP, and potential changes in body composition during the studies. 


\section{EVIDENCE FROM RANDOMIZED-CONTROLLED TRIALS}

To date, a total of nine studies using randomized-controlled designs have investigated the effects of CPAP therapy on measures of glucose metabolism (Table 4). All studies included shamCPAP as the control group and most studies were conducted in men. The duration of intervention period varied between 1 week and 3 months. Some studies used a parallel group design (West et al., 2007; Lam et al., 2010; Nguyen et al., 2010; Kohler et al., 2011; Hoyos et al., 2012) in which patients were randomized to either CPAP or sham-CPAP, while others used a cross-over design (Coughlin et al., 2007; Sharma et al., 2011; Sivam et al., 2012; Weinstock et al., 2012) where patients were first randomized to CPAP or sham-CPAP, followed by the alternate therapy after a washout period. In six of the nine studies (Coughlin et al., 2007; West et al., 2007; Lam et al., 2010; Sharma et al., 2011; Hoyos et al., 2012; Weinstock et al., 2012), measures of glucose metabolism were used as primary outcome, whereas in the remaining three studies, fasting glucose (Nguyen et al., 2010; Sivam et al., 2012) and HOMA index (Kohler et al., 2011) were included as secondary outcomes. Overall, only three of the nine studies (Lam et al., 2010; Sharma et al., 2011; Weinstock et al., 2012) reported positive findings during the randomized treatment period. One study (Hoyos et al., 2012) had positive findings only in the open, non-randomized extended portion of CPAP therapy. Nightly treatment use (CPAP or shamCPAP) was $5 \mathrm{~h}$ or less in most studies (Coughlin et al., 2007; West et al., 2007; Nguyen et al., 2010; Sharma et al., 2011; Hoyos et al., 2012; Sivam et al., 2012; Weinstock et al., 2012) except about $6 \mathrm{~h}$ in one study (Kohler et al., 2011), which a priori included patients who had been treated with CPAP for more than 12 months with an average compliance of $4 \mathrm{~h} /$ night. In another study with only 1 week of intervention, CPAP use, but not sham-CPAP, averaged about $6 \mathrm{~h}$ (Lam et al., 2010). Sample characteristics, OSA definition, measures of glucose metabolism, randomized treatment duration, nightly treatment hours, and main findings on glucose metabolism and other key outcomes from the nine randomized-controlled trials are summarized in Table 4.

West et al. (2007) studied 42 obese patients with type 2 diabetes in a double-blind parallel-design and found no effect of CPAP on A1c levels or insulin sensitivity (estimated by the euglycemic clamp method), but reported significant improvements in daytime sleepiness (assessed by the Epworth Sleepiness Scale and the Maintenance Wakefulness Test) after 3 months of CPAP. Body composition including BMI, percent body fat (by bioimpedance technique), waist-hip ratio, and neck size did not change with treatment. In this study, the average nightly CPAP use was only about $3.3 \mathrm{~h}$ and no correlation was reported between CPAP compliance and measures of insulin resistance and A1c (West et al., 2007).

Coughlin et al. (2007) investigated the effect of 6 weeks of CPAP versus sham-CPAP in a cross-over design on cardiovascular and metabolic outcomes in 34 obese (mean BMI $=36.1 \mathrm{~kg} / \mathrm{m}^{2}$ ) and non-diabetic men with symptomatic OSA. The authors found no significant difference in insulin sensitivity (as assessed by the HOMA index) or the presence of metabolic syndrome after CPAP use. Similar to the study by West et al. (2007), the average CPAP use was low, averaging about $3.9 \mathrm{~h} /$ night. Despite the relatively poor CPAP compliance, there was a significant improvement in blood pressure (Coughlin et al., 2007), suggesting that the amount and the duration needed to reverse cardiovascular and metabolic abnormalities may differ.

In a parallel-design study by Lam et al. (2010), 61 non-diabetic Chinese men with moderate to severe OSA and lesser degree of obesity (mean BMI $=27.5 \mathrm{~kg} / \mathrm{m}^{2}$ ) were randomized to either CPAP or sham-CPAP for only 1 week. Those who were in the CPAP group were also re-assessed at 3 months. Insulin sensitivity was estimated by the short insulin tolerance test and the HOMA index. After 1 week of treatment, the CPAP group (about $6.2 \mathrm{~h}$ of average CPAP use) showed reduced insulin resistance and this improvement in insulin sensitivity was maintained at 3 months in those who were overweight (BMI of 25 or greater). After 3 months of CPAP use, there were improvements in blood pressure, plasma lipids, and urinary catecholamines, but no change was observed in the amount of visceral fat as measured by MRI (Lam et al., 2010).

In a small study with a parallel design, Nguyen et al. (2010) randomized 20 newly diagnosed, moderate to severe OSA patients to either CPAP or sham-CPAP for 3 months to investigate the impact of CPAP therapy on myocardial and endothelial function as main outcomes. While parameters of cardiovascular function improved after CPAP, there was no change in fasting glucose levels, which was included in the study as a secondary outcome.

In the largest trial, Sharma et al. (2011) studied 86 patients with severe OSA, of which the majority ( $87 \%$ ) had metabolic syndrome and about $50 \%$ were diabetics. The patients were randomly assigned to 3 months of CPAP followed by 3 months of shamCPAP, or vice versa, with a washout period of 1 month in between. The frequency of the metabolic syndrome was reduced after CPAP therapy with reversal found in 11 of 86 patients (13\%) undergoing CPAP therapy versus 1 of 86 (1\%) undergoing sham-CPAP. A1c was slightly but significantly improved after CPAP compared to sham-CPAP, but no significant differences were observed in fasting glucose and insulin levels or insulin resistance as assessed by HOMA index. The authors also observed small, but significant reductions in blood pressure, lipids, and BMI $(-0.3$ unit difference between CPAP versus sham-CPAP groups) as well as reductions in visceral and subcutaneous fat, quantified by computerized tomography.

Weinstock et al. (2012) randomized 50 patients (mean $\mathrm{BMI}=39 \mathrm{~kg} / \mathrm{m}^{2}$ ) with prediabetes and moderate to severe OSA to either 2 months of CPAP or sham-CPAP in a cross-over design with a 1-month washout period. Prior to randomization, each patient was enrolled in a 2 -week run-in period, and only those who met minimal adherence criteria during the run-in period were then randomized. The primary outcome was normalization of IGT status as assessed by $2 \mathrm{~h}$ glucose levels during an OGTT. Although the study did not show that IGT normalizes after CPAP (average use was $4.8 \mathrm{~h}$ in the CPAP group), there was improvement in insulin sensitivity (assessed by the Gutt index) and $2 \mathrm{~h}$ insulin levels in a subgroup of patients with severe OSA who had an AHI of 30 or greater. Notably, for each hour of CPAP use, the mean change in insulin sensitivity from baseline increased by $4.2 \%$. Interestingly, sleepy patients with an Epworth Sleepiness score of 16 or greater had larger improvements in insulin sensitivity, fasting insulin, and 2-h insulin as compared to non-sleepy subjects. This study also controlled for individual differences in sleep duration 


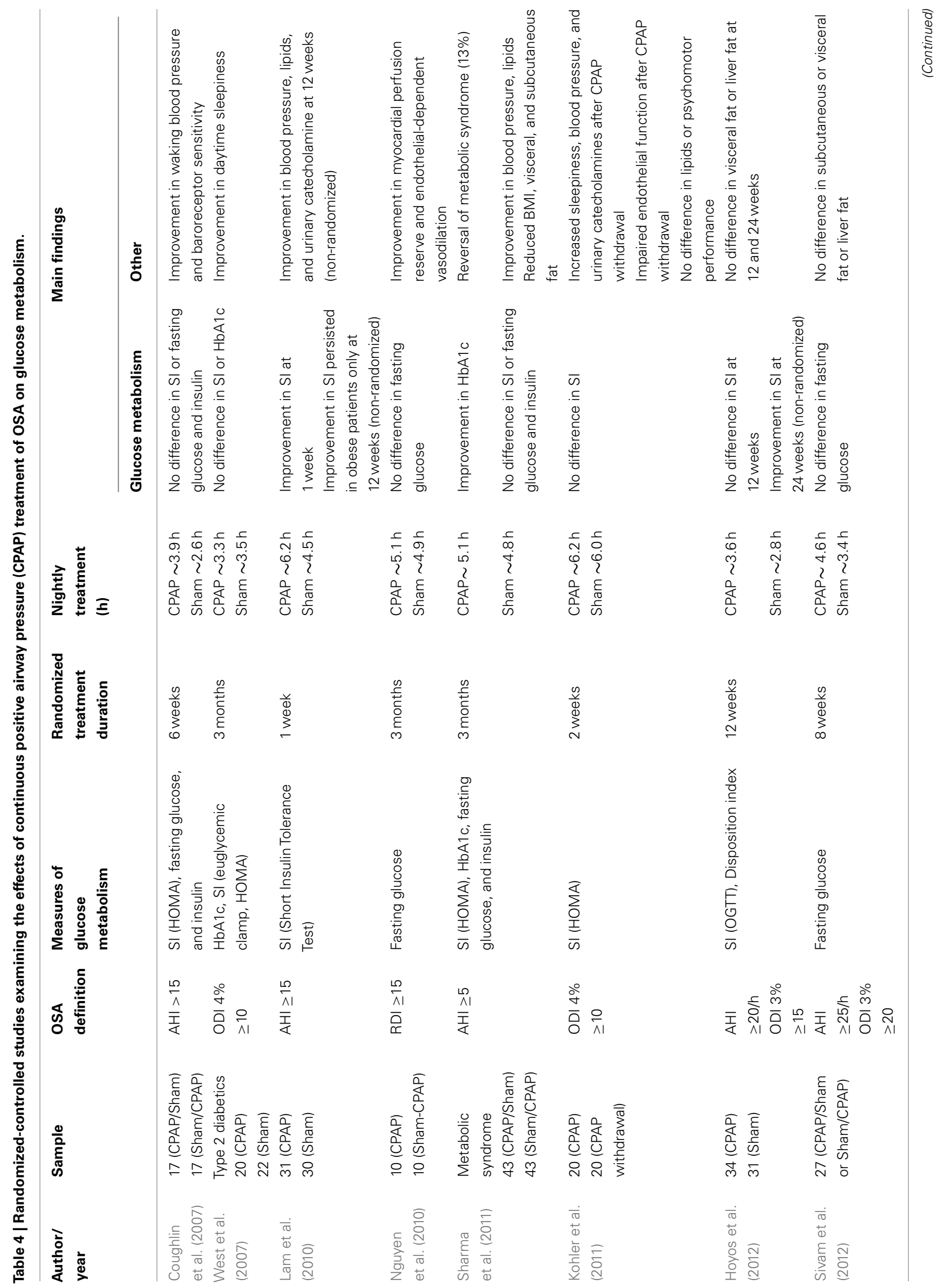




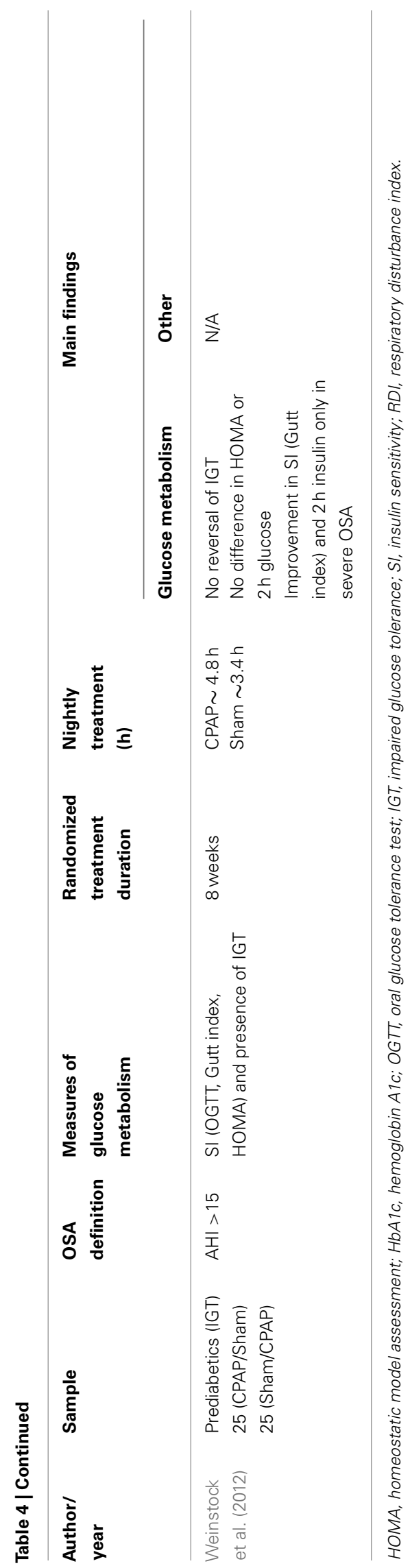

and visceral fat (as assessed by computerized tomography) in the analyses.

In the study by Kohler et al. (2011) 41 patients with OSA who were treated with CPAP were randomized to either CPAP withdrawal (sub-therapeutic CPAP), or continued CPAP, for 2 weeks. CPAP withdrawal resulted in rapid recurrence of OSA, increased subjective sleepiness, impaired endothelial function, increased urinary catecholamines, and elevated blood pressure and heart rate. However, there was no change in lipids or insulin sensitivity as estimated by the HOMA index.

Sivam et al. (2012) studied 27 patients who received both therapeutic and sham-CPAP in random order for 2 months with an intervening 1 month washout period. No difference was found in subcutaneous, visceral, and liver fat (primary outcomes) or fasting glucose levels (secondary outcome) between treatment arms.

The study by Hoyos et al. (2012) included 65 non-diabetic, obese men (mean $\mathrm{BMI}=31.3 \mathrm{~kg} / \mathrm{m}^{2}$ ) with moderate to severe OSA who were randomized to therapeutic or sham-CPAP for 3 months in a parallel group design. At the end of 3 months, all patients received therapeutic CPAP for an additional 3 months. The primary outcomes (from baseline to 12 weeks) were the change in visceral fat by computerized tomography and the change in insulin sensitivity based on OGTT. Although there were no differences in insulin sensitivity between the two groups after 12 weeks, the entire group using CPAP showed improved insulin sensitivity as compared to baseline at the end of 24 weeks during the non-randomized portion of the study (Hoyos et al., 2012). Of note, the therapeutic CPAP pressure was determined by an athome titration, which may not be optimal, and the average CPAP use was only $3.6 \mathrm{~h}$. Even though subgroup analyses were performed in "more compliant" patients (average use $>4 \mathrm{~h} /$ night), there were only 5 out of $65(8 \%)$ patients who used CPAP for more than $6 \mathrm{~h}$.

In conclusion, there is still controversy as to whether CPAP treatment of OSA improves glucose metabolism. There is some evidence to support the hypothesis that the degree of obesity and the amount of CPAP use may be important factors in the metabolic response to CPAP. The current data also suggest that the effects of CPAP may vary according to the measured outcome. Large-scale randomized-controlled trials with robust assessments of insulin sensitivity and glucose tolerance will be required to fully determine the metabolic effects of CPAP. Moreover, future studies are also needed to investigate the optimal duration and the amount of CPAP use that is required to improve metabolic outcomes. Such interventional studies would be essential to address whether there is a causal link between OSA and alterations in glucose metabolism. Future studies should aim to determine subgroups of OSA patients who possess certain characteristics that make them more likely to get metabolic benefit from CPAP therapy. Identification of these metabolic phenotypes of OSA who are responsive to CPAP therapy could be a key factor in the clinical management and care of patients with prediabetes and type 2 diabetes.

\section{WHAT ARE THE POTENTIAL MECHANISMS UNDERLYING THE LINK BETWEEN OSA AND INSULIN RESISTANCE AND GLUCOSE INTOLERANCE?}

The two major characteristics of OSA, namely intermittent hypoxia and sleep fragmentation can lead to derangements in 
glucose metabolism by several mechanisms including activations of the sympathetic nervous system and hypothalamic-pituitary axis, and changes in the inflammatory pathways (Jun and Polotsky, 2009). Other putative mechanisms include hypoxic injury to pancreas and potential alterations in central (e.g., hypothalamic) pathways for glucose control. Animal models mimicking OSA have been used to elucidate the potential mechanisms that may be responsible for metabolic dysregulation in OSA. Intermittent hypoxia stimuli of varying frequency and severity were used in rodents when they are most likely to be asleep. In one study, electroencephalogram tracings were recorded and showed that intermittent hypoxia stimuli were accompanied by arousals, suggesting that sleep fragmentation is also an intrinsic feature of these hypoxia models (Polotsky et al., 2006). In these models, intermittent hypoxia led to sympathetic activation and hypertension (Fletcher et al., 1992; Fletcher, 2003), insulin resistance in both lean (Iiyori et al., 2007) and obese (Polotsky et al., 2003) rodents, impaired glucose homeostasis (Yokoe et al., 2008), and pancreatic beta-cell proliferation (Yokoe et al., 2008; Xu et al., 2009) as well as apoptosis of beta-cells (Yokoe et al., 2008; Xu et al., 2009). In a study by Gharib et al. (2012) mice that were exposed to $6 \mathrm{~h}$ of sleep fragmentation by the movement of an automated bar showed insulin resistance and glucose intolerance as well as altered transcriptional profile of visceral adipocytes. In healthy humans, one study that used intermittent hypoxia selectively during sleep found that 2-4 weeks of exposure to intermittent hypoxia resulted in increased morning blood pressure (Tamisier et al., 2009), but glucose metabolism was not assessed. Another study exposed healthy subjects to $5 \mathrm{~h}$ of intermittent hypoxia or normoxia during wakefulness and reported a decreased insulin sensitivity estimated by ivGTT (Louis and Punjabi, 2009). Two studies exposed healthy subjects to sleep fragmentation using acoustic stimuli and examined the effects on glucose metabolism by ivGTT. In the first study by Tasali et al. (2008a), all night selective suppression of slow wave sleep for three consecutive nights resulted in an approximate $25 \%$ decrease in insulin sensitivity without adequate compensatory rise in insulin secretion, leading to reduced glucose tolerance and increased diabetes risk (i.e., decreased disposition index). In the second study, non-selective sleep fragmentation for two nights was associated with a decrease in insulin sensitivity and non-insulin dependent glucose disposal

\section{REFERENCES}

American Diabetes Association (ADA). (2010). Standards of medical care in diabetes - 2010. Diabetes Care 33(Suppl. 1), S11-S61.

Aronsohn, R. S., Whitmore, H., Van Cauter, E., and Tasali, E. (2010). Impact of untreated obstructive sleep apnea on glucose control in type 2 diabetes. Am. J. Respir. Crit. Care Med. 181, 507-513.

Babu, A. R., Herdegen, J., Fogelfeld, L., Shott, S., and Mazzone, T. (2005). Type 2 diabetes, glycemic control, and continuous positive airway pressure in obstructive sleep apnea. Arch. Intern. Med. 165, 447-452.
Barcelo, A., Barbe, F., De La Pena, M., Martinez, P., Soriano, J. B., Pierola, J., and Agusti, A. G. (2008). Insulin resistance and daytime sleepiness in patients with sleep apnoea. Thorax 63, 946-950.

Bergman, R. N. (2005). Minimal model: perspective from 2005. Horm. Res. 64(Suppl. 3), 8-15.

Botros, N., Concato, J., Mohsenin, V., Selim, B., Doctor, K., and Yaggi, H. K. (2009). Obstructive sleep apnea as a risk factor for type 2 diabetes. Am. J. Med. 122, 1122-1127.

Brooks, B., Cistulli, P. A., Borkman, M., Ross, G., McGhee, S., Grunstein, R. R., Sullivan, C. E., and Yue, D. K. (1994). Obstructive sleep apnea

(Stamatakis and Punjabi, 2009). In contrast to the study by Tasali et al. the second study noted an increase in the acute insulin response to glucose, suggesting that the beta-cell function was preserved. Notably, the second study was also associated with marked reductions in slow wave sleep, whereas other sleep stages were only minimally affected. Both of these sleep fragmentation studies were associated with elevated cardiac sympathetic output (Tasali et al., 2008a; Stamatakis and Punjabi, 2009). Overall, data from animal and human models that mimic OSA support an adverse effect of OSA on insulin resistance, glucose intolerance, and increased diabetes risk. The relative contributions of intermittent hypoxia versus sleep fragmentation on cardiometabolic outcomes remain to be determined.

In summary, current evidence strongly supports an independent association between OSA and insulin resistance and glucose intolerance, but a causal link remains to be determined. A substantial proportion of patients with type 2 diabetes suffer from unrecognized OSA. Conversely, type 2 diabetes is more prevalent among patients with OSA compared to those without OSA. Thus, the role of OSA in the management of type 2 diabetes is in urgent need of further rigorous assessment. The question of whether OSA represents an independent risk for the development of prediabetes and type 2 diabetes over time remains to be investigated by large prospective studies. Notably, weight loss, if successfully achieved can improve both OSA and glucose control, and thus should be recommended systematically to all patients with OSA. There is still debate whether CPAP treatment of OSA improves glucose metabolism. Also, the sufficient amount and duration of CPAP that is required to improve metabolic outcomes remains to be determined. Large-scale randomized-controlled trials of CPAP treatment of OSA with well-validated assessments of insulin sensitivity and glucose tolerance are needed. Identification of phenotypes of OSA patients who show better metabolic response to CPAP therapy would be important.

\section{ACKNOWLEDGMENTS}

The authors would like to acknowledge the grant support from the National Institutes of Health R01 HL086459, RC1HL100046-01, P01 AG11412, P50 HD057796, and CTSA UL1 RR024999 as well as the Diabetes Research and Training Center at the University of Chicago.

in obese noninsulin-dependent diabetic patients: effect of continuous positive airway pressure treatment on insulin responsiveness. J. Clin Endocrinol. Metab. 79, 1681-1685.

Carneiro, G., Togeiro, S. M., RibeiroFilho, F. F., Truksinas, E., Ribeiro, A. B., Zanella, M. T., and Tufik, S. (2009). Continuous positive airway pressure therapy improves hypoadiponectinemia in severe obese men with obstructive sleep apnea without changes in insulin resistance. Metab. Syndr. Relat. Disord. 7, 537-542.

Celen, Y. T., Hedner, J., Carlson, J., and Peker, Y. (2010). Impact of gender on incident diabetes mellitus in obstructive sleep apnea: a 16year follow-up. J. Clin. Sleep Med. 6, 244-250.

Center for Disease Control (CDC). (2011). National Diabetes Fact Sheet, 2011. Atlanta: Department of Health and Human Services, Center for Disease Control and Prevention.

Comondore, V. R., Cheema, R., Fox, J., Butt, A., John Mancini, G. B. Fleetham, J. A., Ryan, C. F., Chan, S., and Ayas, N. T. (2009). The impact of CPAP on cardiovascular biomarkers in minimally symptomatic patients with obstructive sleep apnea: a pilot feasibility randomized crossover trial. Lung 187, 17-22. 
Cooper, B. G., White, J. E. S., Ashworth, L. A., Alberti, K. G. M. M., and Gibson, G. J. (1995). Hormonal and metabolic profiles in subjects with obstructive sleep apnea syndrome and the effects of nasal continuous positive airway pressure (CPAP) treatment. Sleep 18, 172-179.

Coughlin, S. R., Mawdsley, L., Mugarza, J. A., Wilding, J. P., and Calverley, P. M. (2007). Cardiovascular and metabolic effects of CPAP in obese men with OSA. Eur. Respir. J. 29, 720-727.

Cuhadaroglu, C., Utkusavas, A., Ozturk, L., Salman, S., and Ece, T. (2009). Effects of nasal CPAP treatment on insulin resistance, lipid profile, and plasma leptin in sleep apnea. Lung 187, 75-81.

Czupryniak, L., Loba, J., Pawlowski, M., Nowak, D., and Bialasiewicz, P. (2005). Treatment with continuous positive airway pressure may affect blood glucose levels in nondiabetic patients with obstructive sleep apnea syndrome. Sleep 28, 601-603.

Dawson, A., Abel, S. L., Loving, R. T., Dailey, G., Shadan, F. F., Cronin, J. W., Kripke, D. F., and Kline, L. E. (2008). CPAP therapy of obstructive sleep apnea in type 2 diabetics improves glycemic control during sleep. J. Clin. Sleep Med. 4, 538-542.

DeFronzo, R., Tobin, J., and Andres, R. (1979). Glucose clamp technique: a method for quantifying insulin secretion and resistance. Am. J. Physiol. 237, E214-E223.

DeFronzo, R. A., and Abdul-Ghani, M. A. (2011). Preservation of beta-cell function: the key to diabetes prevention. J. Clin. Endocrinol. Metab. 96, 2354-2366.

Dorkova, Z., Petrasova, D., Molcanyiova, A., Popovnakova, M., and Tkacova, R. (2008). Effects of CPAP on cardiovascular risk profile in patients with severe obstructive sleep apnea and metabolic syndrome. Chest 134, 686-692.

Einhorn, D., Stewart, D. A., Erman, M. K., Gordon, N., Philis-Tsimikas, A., and Casal, E. (2007). Prevalence of sleep apnea in a population of adults with type 2 diabetes mellitus. Endocr. Pract. 13, 355-362.

Fendri, S., Rose, D., Myambu, S., Jeanne, S., and Lalau, J. D. (2011). Nocturnal hyperglycaemia in type 2 diabetes with sleep apnoea syndrome. Diabetes Res. Clin. Pract. 91, e21-e23.

Fletcher, E. C. (2003). Sympathetic over activity in the etiology of hypertension of obstructive sleep apnea. Sleep 26, 15-19.

Fletcher, E. C., Lesske, J., Culman, J., Miller, C. C., and Unger, T.
(1992). Sympathetic denervation blocks blood pressure elevation in episodic hypoxia. Hypertension 20, 612-619.

Foster, G. D., Sanders, M. H., Millman, R., Zammit, G., Borradaile, K. E., Newman, A. B., Wadden, T. A., Kelley, D., Wing, R. R., Sunyer, F. X., Darcey, V., and Kuna, S. T. (2009). Obstructive sleep apnea among obese patients with type 2 diabetes. Diabetes Care 32, 1017-1019.

Fredheim, J. M., Rollheim, J., Omland, T., Hofso, D., Roislien, J., Vegsgaard, K., and Hjelmesaeth, J. (2011). Type 2 diabetes and pre-diabetes are associated with obstructive sleep apnea in extremely obese subjects: a crosssectional study. Cardiovasc. Diabetol. 10,84 .

Garcia, J. M., Sharafkhaneh, H., Hirshkowitz, M., Elkhatib, R., and Sharafkhaneh, A. (2011). Weight and metabolic effects of CPAP in obstructive sleep apnea patients with obesity. Respir. Res. 12, 80.

Gharib, S. A., Khalyfa, A., Abdelkarim, A., Bhushan, B., and Gozal, D. (2012). Integrative miRNAmRNA profiling of adipose tissue unravels transcriptional circuits induced by sleep fragmentation. PLoS ONE 7, e37669. doi:10.1371/journal.pone.0037669

Harsch, I. A., Schahin, S. P., Bruckner, K., Radespiel-Troger, M., Fuchs, F. S., Hahn, E. G., Konturek, P. C., Lohmann, T., and Ficker, J. H. (2004). The effect of continuous positive airway pressure treatment on insulin sensitivity in patients with obstructive sleep apnoea syndrome and type 2 diabetes. Respiration 71, 252-259.

Heffner, J. E., Rozenfeld, Y., Kai, M., Stephens, E. A., and Brown, L. K. (2012). Prevalence of diagnosed sleep apnea among patients with type 2 diabetes in primary care. Chest 141, 1414-1421.

Henley, D. E., Russell, G. M., Douthwaite, J. A., Wood, S. A., Buchanan, F., Gibson, R., Woltersdorf, W. W., Catterall, J. R., and Lightman, S. L. (2009). Hypothalamic-pituitaryadrenal axis activation in obstructive sleep apnea: the effect of continuous positive airway pressure therapy. J. Clin. Endocrinol. Metab. 94, 4234-4242.

Hoyos, C. M., Killick, R., Yee, B. J., Phillips, C. L., Grunstein, R. R., and Liu, P. Y. (2012). Cardiometabolic changes after continuous positive airway pressure for obstructive sleep apnoea: a randomised shamcontrolled study. Thorax. doi: 10.1111/j.1365-2265.2012.04413.x. [Epub ahead of print].

Iiyori, N., Alonso, L. C., Li, J., Sanders, M. H., Garcia-Ocana, A., O’Doherty, R. M., Polotsky, V. Y., and O'Donnell, C. P. (2007). Intermittent hypoxia causes insulin resistance in lean mice independent of autonomic activity. Am. J. Respir. Crit. Care Med. 175, 851-857.

Ip, S., Lam, B., Ng, M., Lam, W., Tsang, K., and Lam, K. (2002). Obstructive sleep apnea is independently associated with insulin resistance. Am. J. Respir. Crit. Care Med. 165, 670-676.

Ip, S., Lam, K., Ho, C., Tsang, K., and Lam, W. (2000). Serum leptin and vascular risk factors in obstructive sleep apnea. Chest 118, 580-586.

Jun, J., and Polotsky, V. Y. (2009). Metabolic consequences of sleepdisordered breathing. ILAR J. 50, 289-306.

Kashyap, S. R., and Defronzo, R. A. (2007). The insulin resistance syndrome: physiological considerations. Diab. Vasc. Dis. Res. 4, 13-19.

Knowler, W. C., Barrett-Connor, E., Fowler, S. E., Hamman, R. F., Lachin, J. M., Walker, E. A., and Nathan, D. M. (2002). Reduction in the incidence of type 2 diabetes with lifestyle intervention or metformin. N. Engl. J. Med. 346, 393-403.

Knowler, W. C., Fowler, S. E., Hamman, R. F., Christophi, C. A., Hoffman, H. J., Brenneman, A. T., BrownFriday, J. O., Goldberg, R., Venditti, E., and Nathan, D. M. (2009). 10year follow-up of diabetes incidence and weight loss in the Diabetes Prevention Program Outcomes Study. Lancet 374, 1677-1686.

Kohler, M., Stoewhas, A. C., Ayers, L. Senn, O., Bloch, K. E., Russi, E. W., and Stradling, J. R. (2011). Effects of continuous positive airway pressure therapy withdrawal in patients with obstructive sleep apnea: a randomized controlled trial. Am. J. Respir. Crit. Care Med. 184, 1192-1199.

Kono, M., Tatsumi, K., Saibara, T., Nakamura, A., Tanabe, N., Takiguchi, Y., and Kuriyama, T. (2007). Obstructive sleep apnea syndrome is associated with some components of metabolic syndrome. Chest 131, 1387-1392.

Laaban, J. P., Daenen, S., Leger, D., Pascal, S., Bayon, V., Slama, G. and Elgrably, F. (2009). Prevalence and predictive factors of sleep apnoea syndrome in type 2 diabetic patients. Diabetes Metab. 35, 372-377.

Lam, J. C., Lam, B., Yao, T. J., Lai, A. Y., Ooi, C. G., Tam, S., Lam, K. S., and
Ip, M. S. (2010). A randomised controlled trial of nasal continuous positive airway pressure on insulin sensitivity in obstructive sleep apnoea. Eur. Respir. J. 35, 138-145.

Levy, P., Bonsignore, M. R., and Eckel, J. (2009). Sleep, sleep-disordered breathing and metabolic consequences. Eur. Respir. J. 34, 243-260.

Lindberg, E., Berne, C., Elmasry, A., Hedner, J., and Janson, C. (2006). CPAP treatment of a populationbased sample - what are the benefits and the treatment compliance? Sleep Med. 7, 553-560.

Lindberg, E., Theorell-Haglow, J., Svensson, M., Gislason, T., Berne, C., and Janson, C. (2012). Sleep apnea and glucose metabolism - a long-term follow-up in a community-based sample. Chest. doi: 10.1378/chest.11-1844. [Epub ahead of print].

Louis, M., and Punjabi, N. M. (2009). Effects of acute intermittent hypoxia on glucose metabolism in awake healthy volunteers. J. Appl. Physiol. 106, 1538-1544.

Mahmood, K., Akhter, N., Eldeirawi, K. Onal, E., Christman, J. W., Carley, D. W., and Herdegen, J. J. (2009). Prevalence of type 2 diabetes in patients with obstructive sleep apnea in a multi-ethnic sample. J. Clin. Sleep Med. 5, 215-221.

Marshall, N. S., Wong, K. K., Phillips, C. L., Liu, P. Y., Knuiman, M. W., and Grunstein, R. R. (2009). Is sleep apnea an independent risk factor for prevalent and incident diabetes in the Busselton Health Study? J. Clin. Sleep Med. 5, 15-20.

Matthews, D., Hosker, J., Rudenski, A., Naylor, B., Treacher, D., and Turner, R. (1985). Homeostasis model assessment: insulin resistance and beta-cell function from fasting plasma glucose and insulin concentrations in man. Diabetologia 28 , 412-419.

Mazzone, T., Chait, A., and Plutzky, J. (2008). Cardiovascular disease risk in type 2 diabetes mellitus: insights from mechanistic studies. Lancet 371, 1800-1809.

Meslier, N., Gagnadoux, F., Giraud, P., Person, C., Ouksel, H., Urban, T., and Racineux, J. L. (2003). Impaired glucose-insulin metabolism in males with obstructive sleep apnoea syndrome. Eur. Respir. J. 22, 156-160.

Mota, P. C., Drummond, M., Winck, J. C., Santos, A. C., Almeida, J., and Marques, J. A. (2011). APAP impact on metabolic syndrome in obstructive sleep apnea patients. Sleep Breath 15, 665-672. 
Muraki, I., Tanigawa, T., Yamagishi, K., Sakurai, S., Ohira, T., Imano, H., Kitamura, A., Kiyama, M., Sato, S., Shimamoto, T., Konishi, M., and Iso, H. (2010). Nocturnal intermittent hypoxia and the development of type 2 diabetes: the Circulatory Risk in Communities Study (CIRCS). Diabetologia 53, 481-488.

Murri, M., Alcazar-Ramirez, J., GarridoSanchez, L., Linde, F., Alcaide, J., Cardona, F., and Tinahones, F. J. (2009). Oxidative stress and metabolic changes after continuous positive airway pressure treatment according to previous metabolic disorders in sleep apnea-hypopnea syndrome patients. Transl. Res. 154, 111-121.

Nathan, D. M., Davidson, M. B., Defronzo, R. A., Heine, R. J., Henry, R. R., Pratley, R., and Zinman, B. (2007). Impaired fasting glucose and impaired glucose tolerance: implications for care. Diabetes Care 30, 753-759.

Newman, A. B., Foster, G., Givelber, R., Nieto, F. J., Redline, S., and Young, T. (2005). Progression and regression of sleep-disordered breathing with changes in weight: the Sleep Heart Health Study. Arch. Intern. Med. 165, 2408-2413.

Nguyen, P. K., Katikireddy, C. K., McConnell, M. V., Kushida, C., and Yang, P. C. (2010). Nasal continuous positive airway pressure improves myocardial perfusion reserve and endothelial-dependent vasodilation in patients with obstructive sleep apnea. J. Cardiovasc. Magn. Reson. $12,50$.

Nieto, F. J., Peppard, P. E., and Young, T. B. (2009). Sleep disordered breathing and metabolic syndrome. WMJ 108, 263-265.

Oktay, B., Akbal, E., Firat, H., Ardic, S., and Kizilgun, M. (2009). CPAP treatment in the coexistence of obstructive sleep apnea syndrome and metabolic syndrome, results of one year follow up. Acta Clin. Belg. 64, 329-334.

Pallayova, M., Donic, V., and Tomori, Z. (2008). Beneficial effects of severe sleep apnea therapy on nocturnal glucose control in persons with type 2 diabetes mellitus. Diabetes Res. Clin. Pract. 81, e8-e11.

Pamidi, S., Aronsohn, R. S., and Tasali, E. (2010). Obstructive sleep apnea: role in the risk and severity of diabetes. Best Pract. Res. Clin. Endocrinol. Metab. 24, 703-715.

Pamidi, S., Wroblewski, K., Broussard, J., Day, A., Hanlon, E., Abraham, V., and Tasali, E. (2012). Obstructive sleep apnea in young lean men: impact on insulin sensitivity and secretion. Diabetes Care (in press)

Peppard, P., Young, T., Palta, M., Dempsey, J., and Skatrud, J. (2000) Longitudinal study of moderate weight change and sleep-disordered breathing. JAMA 284, 3015-3021.

Pillai, A., Warren, G., Gunathilake, W., and Idris, I. (2011). Effects of sleep apnea severity on glycemic control in patients with type 2 diabetes prior to continuous positive airway pressure treatment. Diabetes Technol. Ther. 13, 945-949.

Polotsky, V. Y., Li, J., Punjabi, N. M., Rubin, A. E., Smith, P. L., Schwartz, A. R., and O'Donnell C. P. (2003). Intermittent hypoxia increases insulin resistance in genetically obese mice. J. Physiol. (Lond.) 552, 253-264.

Polotsky, V. Y., Rubin, A. E., Balbir, A., Dean, T., Smith, P. L., Schwartz, A. R., and O'Donnell, C. P. (2006) Intermittent hypoxia causes REM sleep deficits and decreases EEG delta power in NREM sleep in the C57BL/6J mouse. Sleep Med.7,7-16.

Priou, P., Le Vaillant, M., Meslier, N., Chollet, S., Masson, P., Humeau, M. P., Pigeanne, T., Bizieux-Thaminy, A., Goupil, F., and Gagnadoux, F. (2012). Independent association between obstructive sleep apnea severity and glycated hemoglobin in adults without diabetes. Diabetes Care. PMID: 22688546. [Epub ahead of print].

Punjabi, N. M. (2009). Do sleep disorders and associated treatments impact glucose metabolism? Drugs 69(Suppl. 2), 13-27.

Punjabi, N. M., and Beamer, B. A. (2009). Alterations in glucose disposal in sleep-disordered breathing. Am. J. Respir. Crit. Care Med. 179, 235-240.

Punjabi, N. M., and Polotsky, V. Y. (2005). Disorders of glucose metabolism in sleep apnea. J. Appl. Physiol. 99, 1998-2007.

Punjabi, N. M., Shahar, E., Redline, S., Gottlieb, D. J., Givelber, R., and Resnick, H. E. (2004). Sleepdisordered breathing, glucose intolerance, and insulin resistance: the Sleep Heart Health Study. Am. J. Epidemiol. 160, 521-530.

Punjabi, N. M., Sorkin, J. D., Katzel, L. I., Goldberg, A. P., Schwartz, A. R., and Smith, P. L. (2002). Sleep-disordered breathing and insulin resistance in middle-aged and overweight men. Am. J. Respir. Crit. Care Med. 165, 677-682.

Redline, S., Kapur, V. K., Sanders, M. H., Quan, S. F., Gottlieb, D. J., Rapoport,
D. M., Bonekat, W. H., Smith, P. L., Kiley, J. P., and Iber, C. (2000). Effects of varying approaches for identifying respiratory disturbances on sleep apnea assessment. Am. J. Respir. Crit. Care Med. 161, 369-374.

Redline, S., Yenokyan, G., Gottlieb, D. J., Shahar, E., O'Connor, G. T. Resnick, H. E., Diener-West, M., Sanders, M. H., Wolf, P. A., Geraghty, E. M., Ali, T., Lebowitz, M., and Punjabi, N. M. (2010). Obstructive sleep apnea-hypopnea and incident stroke: the sleep heart health study. Am. J. Respir. Crit. Care Med. 182, 269-277.

Reichmuth, K. J., Austin, D., Skatrud J. B., and Young, T. (2005). Association of sleep apnea and type II diabetes: a population-based study. Am. J. Respir. Crit. Care Med. 172, 1590-1595.

Resnick, H. E., Redline, S., Shahar, E., Gilpin, A., Newman, A., Walter, R., Ewy, G. A., Howard, B. V., and Punjabi, N. M. (2003). Diabetes and sleep disturbances: findings from the Sleep Heart Health Study. Diabetes Care 26, 702-709.

Ronksley, P. E., Hemmelgarn, B. R. Heitman, S. J., Hanly, P. J., Faris, P. D., Quan, H., and Tsai, W. H. (2009). Obstructive sleep apnoea is associated with diabetes in sleepy subjects. Thorax 64, 834-839.

Saarelainen, S., Lahtela, J., and Kallonen, E. (1997). Effect of nasa CPAP treatment on insulin sensitivity and plasma leptin. J. Sleep Res. 6 , 146-147.

Saini, J., Krieger, J., Brandenberger, G., Wittersheim, G., Simon, C., and Follenius, M. (1993). Continuous positive airway pressure treatment: effects on growth hormone, insulin and glucose profiles in obstructive sleep apnea patients. Horm. Metab. Res. 25, 375-381.

Samson, P., Casey, K. R., Knepler, J. and Panos, R. J. (2012). Clinical characteristics, comorbidities, and response to treatment of veterans with obstructive sleep apnea, Cincinnati Veterans Affairs Medical Center, 2005-2007. Prev. Chronic. Dis. 9, E46.

Schahin, S. P., Nechanitzky, T., Dittel, C., Fuchs, F. S., Hahn, E. G., Konturek, P. C., Ficker, J. H., and Harsch, I. A. (2008). Long-term improvement of insulin sensitivity during CPAP therapy in the obstructive sleep apnoea syndrome. Med. Sci. Monit. 14, CR117-CR121.

Seicean, S., Kirchner, H. L., Gottlieb, D. J., Punjabi, N. M., Resnick, H., Sanders, M., Budhiraja, R., Singer, M., and Redline, S. (2008). Sleep disordered breathing and impaired glucose metabolism in normal weight and overweight/obese individuals: the Sleep Heart Health Study. Diabetes Care 31, 1001-1006. Sharma, S. K., Agrawal, S., Damodaran, D., Sreenivas, V., Kadhiravan, T., Lakshmy, R., Jagia, P., and Kumar, A. (2011). CPAP for the metabolic syndrome in patients with obstructive sleep apnea. N. Engl. J. Med. 365, 2277-2286.

Shaw, J. E., Punjabi, N. M., Wilding, J. P., Alberti, K. G., and Zimmet, P. Z. (2008). Sleep-disordered breathing and type 2 diabetes: a report from the International Diabetes Federation Taskforce on Epidemiology and Prevention. Diabetes Res. Clin. Pract. 81, 2-12.

Shpirer, I., Rapoport, M. J., Stav, D., and Elizur, A. (2012). Normal and elevated $\mathrm{HbA1C}$ levels correlate with severity of hypoxemia in patients with obstructive sleep apnea and decrease following CPAP treatment. Sleep Breath 16, 461-466.

Sivam, S., Phillips, C. L., Trenell, M. I., Yee, B. J., Liu, P. Y., Wong, K. K., and Grunstein, R. R. (2012). Effects of 8 weeks of CPAP on abdominal adiposity in obstructive sleep apnoea. Eur. Respir. J. PMID: 22267762. [Epub ahead of print].

Smurra, M., Philip, P., Taillard, J., Guilleminault, C., Bioulac, B., and Gin, H. (2001). CPAP treatment does not affect glucose-insulin metabolism in sleep apneic patients. Sleep Med. 2, 207-213.

Somers, V. K., White, D. P., Amin, R., Abraham, W. T., Costa, F., Culebras, A., Daniels, S., Floras, J. S., Hunt, C. E., Olson, L. J., Pickering, T. G., Russell, R., Woo, M., and Young, T. (2008). Sleep apnea and cardiovascular disease: an American Heart Association/American College of Cardiology Foundation Scientific Statement from the American Heart Association Council for High Blood Pressure Research Professional Education Committee, Council on Clinical Cardiology, Stroke Council, and Council on Cardiovascular Nursing. J. Am. Coll. Cardiol. 52, 686-717.

Stamatakis, K. A., and Punjabi, N. M. (2009). Effects of sleep fragmentation on glucose metabolism in normal subjects. Chest 137, 95-101.

Steiropoulos, P., Kotsianidis, I., Nena, E., Tsara, V., Gounari, E., Hatzizisi, O., Kyriazis, G., Christaki, P., Froudarakis, M., and Bouros, D. (2009a). Long-term effect of continuous positive airway pressure therapy on inflammation markers of 
patients with obstructive sleep apnea syndrome. Sleep 32, 537-543.

Steiropoulos, P., Papanas, N., Nena, E., Tsara, V., Fitili, C., Tzouvelekis, A., Christaki, P., Maltezos, E., and Bouros, D. (2009b). Markers of glycemic control and insulin resistance in non-diabetic patients with Obstructive Sleep Apnea Hypopnea Syndrome: does adherence to CPAP treatment improve glycemic control? Sleep Med. 10, 887-891.

Stoohs, R., Facchini, F., and Guilleminault, C. (1996). Insulin resistance and sleep-disordered breathing in healthy humans. Am. J. Respir. Crit. Care Med. 154, 170-174.

Tamisier, R., Gilmartin, G. S., Launois, S. H., Pepin, J. L., Nespoulet, H., Thomas, R., Levy, P., and Weiss, J. W. (2009). A new model of chronic intermittent hypoxia in humans: effect on ventilation, sleep, and blood pressure. J. Appl. Physiol. 107, 17-24.

Tamura, A., Kawano, Y., Watanabe, T., and Kadota, J. (2008). Relationship between the severity of obstructive sleep apnea and impaired glucose metabolism in patients with obstructive sleep apnea. Respir. Med. 102, 1412-1416.

Tasali, E., Chapotot, F., Leproult, R., Whitmore, H., and Ehrmann, D. A. (2011). Treatment of obstructive sleep apnea improves cardiometabolic function in young obese women with polycystic ovary syndrome. J. Clin. Endocrinol. Metab. $96,365-374$
Tasali, E., and Ip, M. S. (2008). Obstructive sleep apnea and metabolic syndrome: alterations in glucose metabolism and inflammation. Proc. Am. Thorac. Soc. 5, 207-217.

Tasali, E., Leproult, R., Ehrmann, D. A., and Van Cauter, E. (2008a). Slowwave sleep and the risk of type 2 diabetes in humans. Proc. Natl. Acad. Sci. U.S.A. 105, 1044-1049.

Tasali, E., Mokhlesi, B., and Van Cauter, E. (2008b). Obstructive sleep apnea and type 2 diabetes: interacting epidemics. Chest 133, 496-506.

Theorell-Haglow, J., Berne, C., Janson, C., Svensson, M., and Lindberg, E. (2006). Is obstruction sleep apnea associated with the metabolic syndrome and impaired glucose metabolism. Sleep Med. 7(Suppl. 2), S5.

Trenell, M. I., Ward, J. A., Yee, B. J., Phillips, C. L., Kemp, G. J., Grunstein, R. R., and Thompson, C. H. (2007). Influence of constant positive airway pressure therapy on lipid storage, muscle metabolism and insulin action in obese patients with severe obstructive sleep apnoea syndrome. Diabetes Obes. Metab. 9 , 679-687.

Tuomilehto, J., Lindstrom, J., Eriksson, J. G., Valle, T. T., Hamalainen, H., Ilanne-Parikka, P., KeinanenKiukaanniemi, S., Laakso, M., Louheranta, A., Rastas, M., Salminen, V., and Uusitupa, M. (2001). Prevention of type 2 diabetes mellitus by changes in lifestyle among subjects with impaired glucose tolerance. N. Engl. J. Med. 344 1343-1350.

Vgontzas, A. N., Zoumakis, E., Bixler E. O., Lin, H. M., Collins, B., Basta, M., Pejovic, S., and Chrousos, G. P. (2008). Selective effects of CPAP on sleep apnoea-associated manifestations. Eur. J. Clin. Invest. 38 585-595.

Weinstock, T. G., Wang, X., Rueschman, M., Ismail-Beigi, F., Aylor, J., Babineau, D. C., Mehra, R., and Redline, S. (2012). A controlled trial of CPAP therapy on metabolic control in individuals with impaired glucose tolerance and sleep apnea. Sleep 35, 617B-625B.

West, S. D., Nicoll, D. J., Wallace, T. M., Matthews, D. R., and Stradling, J. R. (2007). Effect of CPAP on insulin resistance and $\mathrm{HbAlc}$ in men with obstructive sleep apnoea and type 2 diabetes. Thorax 62, 969-974.

Xu, J., Long, Y. S., Gozal, D., and Epstein P. N. (2009). Beta-cell death and proliferation after intermittent hypoxia: role of oxidative stress. Free Radic Biol. Med. 46, 783-790.

Yaggi, H. K., Concato, J., Kernan, W. N., Lichtman, J. H., Brass, L. M. and Mohsenin, V. (2005). Obstructive sleep apnea as a risk factor for stroke and death. N. Engl. J. Med. 353, 2034-2041.

Yokoe, T., Alonso, L. C., Romano, L. C., Rosa, T. C., O’Doherty, R. M., Garcia-Ocana, A., Minoguchi, K., and O'Donnell, C. P. (2008). Intermittent hypoxia reverses the diurnal glucose rhythm and causes pancreatic beta-cell replication in mice. J. Physiol. (Lond.) 586, 899-911.

Young, T., Finn, L., Peppard, P. E., SzkloCoxe, M., Austin, D., Nieto, F. J., Stubbs, R., and Hla, K. M. (2008). Sleep disordered breathing and mortality: eighteen-year follow-up of the Wisconsin sleep cohort. Sleep 31, 1071-1078.

Young, T., Peppard, P. E., and Taheri, S. (2005). Excess weight and sleepdisordered breathing. J. Appl. Physiol. 99, 1592-1599.

Conflict of Interest Statement: The authors declare that the research was conducted in the absence of any commercial or financial relationships that could be construed as a potential conflict of interest.

Received: 16 June 2012; accepted: 24 July 2012; published online: 13 August 2012. Citation: Pamidi S and Tasali E (2012) Obstructive sleep apnea and type 2 diabetes: is there a link? Front. Neur. 3:126. doi: 10.3389/fneur.2012.00126

This article was submitted to Frontiers in Sleep and Chronobiology, a specialty of Frontiers in Neurology.

Copyright (c) 2012 Pamidi and Tasali. This is an open-access article distributed under the terms of the Creative Commons Attribution License, which permits use, distribution and reproduction in other forums, provided the original authors and source are credited and subject to any copyright notices concerning any third-party graphics etc. 